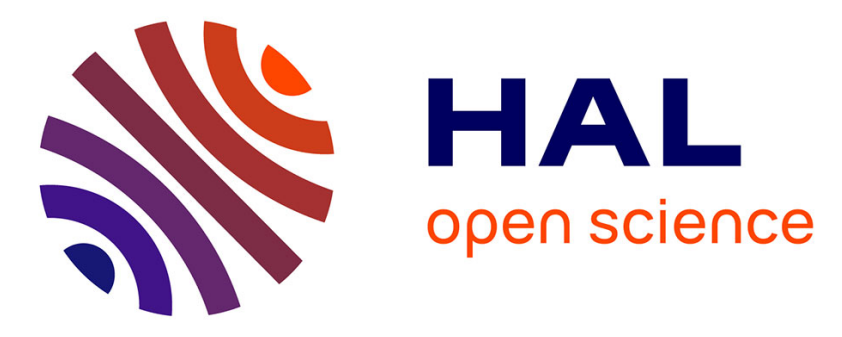

\title{
Efficacy and safety of pallidal stimulation in primary dystonia: results of the Spanish multicentric study
}

Francesc Valldeoriola, Ignacio Regidor, Adolfo Mínguez-Castellanos, Elena

Lezcano, Pedro García-Ruiz, Ana Rojo, Antonio Salvador, Alfonso Castro, Francisco Grandas, Maria José Martí, et al.

\section{To cite this version:}

Francesc Valldeoriola, Ignacio Regidor, Adolfo Mínguez-Castellanos, Elena Lezcano, Pedro GarcíaRuiz, et al.. Efficacy and safety of pallidal stimulation in primary dystonia: results of the Spanish multicentric study. Journal of Neurology, Neurosurgery and Psychiatry, 2009, 81 (1), pp.65. 10.1136/jnnp.2009.174342 . hal-00552775

\section{HAL Id: hal-00552775 https://hal.science/hal-00552775}

Submitted on 6 Jan 2011

HAL is a multi-disciplinary open access archive for the deposit and dissemination of scientific research documents, whether they are published or not. The documents may come from teaching and research institutions in France or abroad, or from public or private research centers.
L'archive ouverte pluridisciplinaire HAL, est destinée au dépôt et à la diffusion de documents scientifiques de niveau recherche, publiés ou non, émanant des établissements d'enseignement et de recherche français ou étrangers, des laboratoires publics ou privés. 


\section{Efficacy and safety of pallidal stimulation in primary dystonia: results of the Spanish multicentric study}

F. Valldeoriola (1), I. Regidor (2), A. Mínguez-Castellanos (3), E. Lezcano (4), P. García-Ruiz (5), A. Rojo (6), A. Salvador (7), A. Castro (8), F. Grandas (9), J. Kulisevsky (10), MJ. Martí (1), P. Martínez-Martín (11), L. Relova (8), J. Rumià (1), A. Cámara (1), JA. Burguera (12), G. Linazasoro (13), J. López de Val (14), J. Obeso (15), MC. Rodríguez-Oroz (15), E. Tolosa (1) and the “Grupo ESpañol para el EStudio de la EStimulación PALidal en la DIStonía” (GESPALDIS)*

*Members of the "GESPALDIS":

C. Magariños, R. Figueiras, L. Cabañes (H. Ramón y Cajal, Madrid); F. Escamilla-Sevilla, MJ. Katati, JM. Martin-Linares (H. Universitario Virgen de las Nieves, Granada); G. Bilbao, I. Lambarri, JC. Gómez, O. Rodriguez, R. Villoria (H. de Cruces, Baracaldo); F. Alonso, J. Ayerbe, J. Muñiz (Fundación Jiménez Díaz, Madrid); B. Oliver, M. Aguilar, D. Badenes (H. Mútua de Terrassa); P. Roldán, F. Talamantes (H. Clínic, València); A. Sésar, M. Gelabert (H. Clínico Universitario, Santiago de Compostela); L. López, S. Giménez-Roldán, F. Garcia (H. Gregorio Marañón, Madrid); A. Gironell, J. Molet, R. B. Pascual-Sedano, R. Rodríguez (Hospital de la Santa Creu i Sant Pau, Barcelona).

1. Hospital Clinic, University of Barcelona

2. Hospital. Ramón y Cajal, Madrid

3. Hospital Universitario Virgen de las Nieves, Granada

4. Hospital de Cruces, Baracaldo

5. Fundación jiménez-Díaz 


\section{Hospital Mútua de Terrassa}

7. Hospital Clínic, València

8. Hospital Universitario, Santiago de Compostela

9. Hospital Gregorio Marañón, Madrid

10. Hospital de la Santa Creu i Sant Pau, Barcelona

11. Instituto Nacional de Epidemiología. CIBERNED. Instituto de Salud Carlos III

12. Hospital La Fe, Valencia

13. Clínica Donosti, San Sebastián

14. Hospital Clínico, Zaragoza

15. Clínica Universitaria de Navarra

Corresponding author: Francesc Valldeoriola, $\mathrm{MD}, \mathrm{PhD}$

Parkinson's Disease and Movement Disorders Unit, Institut Clínic de Neurociències, and Centro de Investigación Biomédica en Red sobre Enfermedades Neurodegenerativas (CIBERNED), Hospital Clínic de Barcelona. Institut d'Investigacions Biomèdiques August Pi i Sunyer, Universitat de Barcelona, Spain. Tel: x-34932275785; Fax: x-34932275783; E-mail: fvallde@ clinic.ub.es

The Corresponding Author has the right to grant on behalf of all authors and does grant on behalf of all authors, an exclusive licence on a worldwide basis to the BMJ Publishing Group Ltd and its Licensees to permit this article (if accepted) to be published in the Journal of Neurology, Neurosurgery \& Psychiatry editions and any other BMJPGL products to exploit all subsidiary rights, as set out in our licence. 


\section{INTRODUCTION}

Dystonia is a complex clinical syndrome originated by a wide range of aetiologies. The diagnosis of dystonia is made after the evaluation of etiological, phenomenological and genetic factors (1). Medications, except in patients with dopa responsive dystonia, are of limited efficacy. Botulinum toxin injections are not applicable to patients with generalized dystonia since many muscular groups contribute to disability (2).

Clinical studies in children and adults with primary generalized dystonia (PGD) have reported beneficial effects of bilateral GPi deep brain stimulation (DBS) in both motor symptoms and disability produced by dystonia (3-5) as well as a favourable impact of DBS in the health related quality of life (HRQoL) (6). Some clinical aspects of GPi stimulation in primary dystonia still remain controversial such as the influence of disease duration or age at onset in determining the post-operative clinical outcome.

We report here the results of a multicentric study designed to assess the tolerability and clinical effects of bilateral pallidal DBS on motor impairment, functional disability, quality of life, pain, and mood in patients with medically refractory primary generalized or segmental dystonia.

\section{PATIENTS AND METHODS}

\section{Study design and patients' eligibility}

The study was a one year observational, prospective, multicenter study with a single therapeutic arm. Open-label, blind, and self-assessed evaluations were applied to investigate the efficacy and safety of bilateral GPi DBS in patients with primary dystonia. 
The study was approved by the ethical committees of participating centres. Informed consent was obtained from each subject. Ten centres participated in this study.

Inclusion criteria were: 1) primary generalized or segmental dystonia; 2) age between 12 and 70 years; 3) disease duration of more than two years; and 4) functional limitation due to dystonic symptoms despite of best medical treatment. Patients with secondary dystonia and patients with focal dystonia or hemidistonia were not eligible for the study. Patients in which fixed dystonic postures had induced permanent skeletal deformities producing severe disability were also excluded. Patients with cognitive impairment $(\mathrm{MMSE}<24)$ or with active psychiatric symptoms were excluded. General conditions limiting life expectancy or structural brain lesions contraindicating surgery were also not eligible.

\section{Clinical assessment}

All patients entering the study were clinically evaluated at baseline, within two weeks before surgery, one month after surgery, and six months and one year after surgery. Evaluations consisted of: a) self-administered scales designed to measure quality of life, pain, caregivers' burden, and mood were used for self-assessment evaluations; b) open-label scores for motor symptoms, disability, and mood disorders were obtained by a designated neurologist in each participating centre following a Spanish version of the Burke-Fahn-Marsden Dystonia Rating Scale (BFMDRS) (7); and c) motor BFMDRS scores were also obtained from independent blind investigators. Structured video recordings were used: films were encrypted in such a way that no reference to the visit number was included. Head and body masking was used to prevent disclosure of operative status or phase of follow-up. References to the specific hospital or the treating practitioner did not appear in any of the videos. Blind evaluators were selected among accredited experts in movement disorders. Before video evaluations, a one day meeting of video rating was performed in order to agree a common protocol for assessing dystonic symptoms in accordance 
with BFMDRS guidelines. Several patients shown in videos were scored independently to obtain inter-rater agreement.

Pain related to dystonia was graded through the Faces Pain Scale, a ten-point scale $(0=$ no pain; 10 = worst pain) (8); HRQoL before and after surgery was analyzed by the validated Spanish version of the Short-Form General Health Survey (SF-36), a generic 36-item health survey $(9,10)$. We also administered the validated Spanish version of the EuroQoL5D (EQ5D) $(11,12)$, a self-reported generic questionnaire measuring HRQoL where health status is divided into five dimensions within three severity levels ( 3 worst-1 best); this includes a visual analogical scale (VAS) scored from 0 (worst) to 100 (best). Caregivers' burden was assessed using a self administered questionnaire, a validated Spanish version of the Zarit Caregiver Burden Scale (13-15). Mood symptoms were evaluated through the Beck's Depression Inventory-II (BDI-II) (16).

Stimulation electrical parameters were adjusted according to the best judgment of local clinical investigators of the study in order to obtain the best clinical outcome while minimizing side effects. Stimulation electrical parameters were recorded at the end of the fist session when the neurostimulators were switched on, at six months, and at one year follow-up.

\section{Data analysis}

Primary outcome measurements were improvement in the motor symptoms, disability (BFMDRS) and HRQoL scores (SF-36 and EuroQoL) in patients with primary dystonia treated with bilateral GPi stimulation. Secondary outcome variables were the safety of bilateral GPi stimulation for the treatment of primary dystonia, assessed by the incidence of permanent Adverse Events, and the effects of the intervention on patients' associated pain, mood and caregivers' burden.

Comparison of clinical, motor, functional and HRQoL measurements was carried out using repeated measures Wilcoxon tests. A two-tailed probability level of 5\% $(p=0.05)$ was considered significant. All statistical tests were two-tailed and were not adjusted for multiple testing. The 
differences in distribution between age at onset of dystonia and duration of the disease with disability scores were analyzed by the ANOVA regression analysis.

Clinical responses were predefined as follows: a) good responders: patients showing more than 50\% improvement on motor BFMDRS scores as judged by blind assessment of standardized videos at one year; b) partial responders: patients improving 25-50\%; c) no responders: patients with less than $25 \%$ of improvement; d) negative changes were considered to be as worsening from the basal condition. Statistical analysis was performed using the SPSS 12.0 software package for Windows (SPSS Inc, Chicago, IL).

\section{RESULTS}

\section{Demographic aspects}

A total of 24 patients were included in the study. Twenty-two patients had PGD, and two patients had primary segmental cervical dystonia. The mean and median age of patients at enrolment was $30 \pm 14$ and 35 \pm 0.5 years respectively. Mean disease duration was $10 \pm 7$ (5-26) years and mean age at onset was $20 \pm 13(13-66)$ years; the ratio of men and women was 1:1. There was a family history of dystonia in 6 patients (25\%). Six patients in the study were DYT-1 positive (25\%).

\section{Outcome}

The results refer to 22 patients since two patients were drop-outs due to adverse effects and were excluded from further analyses. None of the patients presented significant motor or functional changes during the first month after surgery. At this moment, the implanted stimulation electrodes were already in place but neurostimulation had not been yet initiated (Table 1). Clinical effects produced by bilateral GPi DBS, as assessed by the BFMDRS, are shown in Tables 1 and 2. All body segments showed statistically significant improvement in dystonia except the cranial area (eyes, voice, and swallowing). At final follow-up, eight patients presented good clinical response, 
(>50\% BFMDRS motor score); nine patients improved between $25-50 \%$ of the motor BFMDRS (partial responders); and five patients were considered to be non-responders ( $<25 \%$ improvement). Medications for dystonia were globally reduced after surgery.

We found a positive correlation between the improvement of both motor and functional BFMDRS scores and the age of patients at the moment of surgery (Rho Spearman correlation coefficient $=-0.66 ; p=0.001)$; no correlations were found between motor and functional scores and neither age at onset of the disease (Rho Spearman correlation coefficient $=0.14 ; p=0.5$ ) nor disease duration (Rho Spearman correlation coefficient $=0.16 ; p=0.5)$. Improvement of motor scores improvement correlated with the presence of DYT1+ mutation but functional scores did not.

Mean MMSE scores did not change significantly all over the follow-up (basal = 28.86 \pm 2.16 ; final follow-up $=28.23 \pm 2.67$ ). Beck’s Depression Scale scores were 34.87 \pm 12.26 before surgery, and 28.67 \pm 9.58 at six months, and 27.12 \pm 11.03 at twelve months follow-up $(p<0.05)$.

Significant changes were seen after surgery in several areas explored through the SF-36 questionnaire, including general health, physical functioning, bodily pain, and in both physical and emotional role limitations. No significant changes were found in social function, vitality, or mental health (Figure 1). Summated physical domain scores were 36.08 \pm 8.79 and $62.37 \pm 8.41(p<0.01)$ at final follow-up, while the sum of mental domain scores was $51.98 \pm 14.01$ preoperatively and $62 \pm 13.11$ (not significant) at one year visit (Figure 1).

The visual analogue scale of the EQ5D questionnaire was scored $36.25 \pm 22$ in basal assessment, whereas the score increased to $66.77 \pm 18.6$ at six months postoperatively, and to $71.57 \pm 26.47$ at final follow-up $(\mathrm{F}=7.7 ; p=0.0001)$. Mobility, self-care, usual activities, anxiety/depression and pain/discomfort scores also improved after surgery. Correspondingly, the faces pain scale scores improved from $3.95 \pm 2.9$ preoperatively to $1.83 \pm 2$ at six months, and $1.87 \pm 1.7$ at twelve months follow-up $(\mathrm{F}=2.81 ; p=0.03)$.

No changes were found in any item of the Zarit scale before and after surgery (basal score was $45.29 \pm 13.3$, at six months $48.28 \pm 12.9$, and $46.25 \pm 10.8$ at twelve months). 


\section{Adverse effects and complications of therapy}

No mortality was observed during the study. Six of the 24 patients presented adverse events $(25 \%)$. Four of these $(16.6 \%)$ were considered serious adverse events.

In one patient a mild left hemiparesia was observed during the operation. Brain MRI performed immediately after electrode implantation revealed bleeding in the right lenticular nucleus and internal capsule $(1.5 \times 2 \times 2 \mathrm{~cm})$. The motor problem resolved completely three months after surgery. One patient presented with acute reoccurrence of dystonic symptoms two months after GPi because of fracture of the cable, which was explanted and replaced. One patient presented several days after surgery with retroauricular pain in the region of the cables connecting the electrodes with the Kinetra that resolved with symptomatic treatment. Two patients presented transitory dysphagia and dysarthria after surgery. All the above explained complications occurred within the first three months after surgery.

Two patients were drop-outs before the first per protocol follow-up visit: one patient presented an infection in the scalp and the other because of a skin allergic reaction in the area of the Kinetra. Both problems resolved after explantation of the system.

\section{DISCUSSION}

Bilateral GPi DBS significantly improved dystonic symptoms as revealed by both open and blind assessments. Improvement of disability, pain, and mood was also observed. Seventeen of the 22 patients who completed the study achieved good or partial response to pallidal DBS. As previously reported by others (4), this therapy improved dystonia in all body segments except in the cranial region. Five patients were considered not responders. The degree of improvement observed in our patients is similar to that seen in the French and German multicentric studies (4-5). 
We found a positive association between motor improvement with DBS and patients' age at the moment of surgery but not with disease duration or age at onset of dystonic symptoms. The presence of DYT-1 mutation was associated with better motor scores after surgery but not with the improvement of functional scores. Mood showed a mild but significant improvement after surgery, probably reflecting upgrading of motor function. This effect has been also observed in previous studies $(20,21)$. We found a mean $40 \%$ improvement in the physical aspects of the HRQoL, including motor functioning and pain. In contrast, we did not observe significant changes in social function and mental health. Previous studies on HRQoL in PGD had also shown pallidal stimulation to improve more the physical than the mental component of the SF-36 six months after surgery (4-6, 22). Despite the global improvement seen in a majority of patients caregivers' burden did not change after surgery when evaluated through a widely used scale tested in a Spanish population of Parkinson's disease patients (19). In this version, the proposed cut-off to determine caregiver's overload is 47 points (mild $47-55$, intense $>55$, sensitivity $84.6 \%$, specificity $85.3 \%$ the first and $89.7 \%$ and $94.2 \%$ respectively for the second). Since caregivers were subject to a mild overload, the Zarit scale could be not sensitive enough to detect minor changes in caregivers' burden after surgery.

In summary, in the present study GPi DBS proved significantly improved motor symptoms, pain, quality of life and mood. Younger age at the moment of surgery correlates positively with motor and functional outcome. 


\section{REFERENCES}

1 -Albanese A, Barnes MP, Bhatia KP, Fernandez-Alvarez E, Filippini G, Gasser T, Krauss JK, Newton A, Rektor I, Savoiardo M, Valls-Solé J. A systematic review on the diagnosis and treatment of primary (idiopathic) dystonia and dystonia plus syndromes: report of an EFNS/MDS-ES Task Force. Eur J Neurol 2006;13: 433--444.

2 -Jankovic J. Treatment of dystonia. Lancet Neurol 2006;5:864-872.

3 -Coubes P, Roubertie A, Vayssiere N, Hemm S, Echenne B. Treatment of DYT1-generalized dystonia by stimulation of the internal globus pallidus. Lancet 2000;355:2220-21.

4 -Vidailhet M, Vercueil L, Houeto JL, Krystkowiak P, Benabid AL, Cornu P, Lagrange C,et al. Bilateral deep-brain stimulation of the globus pallidus in primary generalized dystonia. N Engl J Med. 2005;352:459-67.

5 -Kupsch A, Benecke R, Muller J, Trottenberg T, Schneider GH, Poewe W, Eisner W, et al. Pallidal deep-brain stimulation in primary generalized or segmental distonia. N Engl J Med. 2006;355:1978-90.

6 -Mueller J, Skogseid IM, Benecke R, Kupsch A, Trottenberg T, Poewe W, Schneider GH, et al. Pallidal deep brain stimulation improves quality of life in segmental and generalized dystonia: results from a prospective, randomized sham-controlled trial. Mov Disord. $2008 ; 23: 131-4$

7 -Burke RE, Fahn S, Marsden CD, Bressman SB, Moskowitz C, Friedman J. Validity and reliability of a rating scale for the primary torsion dystonia. Neurology $1985 ; 35: 73-7$. 8 -Bieri D, Reeve RA, Champion GD, Addicoat L, Ziegler JB. The Faces Pain Scale for the self-assessment of the severity of pain experienced by children: development, initial validation, and preliminary investigation for ratio scale properties. Pain 1990;41:139;41:139-50. 9 -McHorney CA, Ware JE Jr, Lu JF, Sherbourne CD. The MOS 36-item Short-Form Health Survey (SF-36): III. Tests of data quality, scaling assumptions, and reliability across diverse patient groups. Med Care 1994;32:40-66. 
10 -Alonso J, Prieto L, Anto JM. La versión española del SF-36 Health Survey (Cuestionario de Salud SF-36): un instrumento para la medida de los resultados clínicos. Med Clin (Barc) $1995 ; 104: 771-6$.

11 -EuroQol Group. EuroQol - A new facility for the measurement of health-related quality of life. Health Policy1990; 16: 199-208.

12 -Badia X, Roset M, Montserrat S, Herdman M, Segura A. The Spanish version of EuroQol: a description and its applications. European Quality of Life scale. Med Clin (Barc) 1999;112 (Suppl 1):79-85.

13 -Zarit SH, Reever KE, Bach-Peterson J. Relatives of the Impaired Elderly: Correlates of Feelings of Burden. Gerontologist 1980; 20: 649-54.

14 -Izal M, Montorio I. Evaluación del medio y del cuidador del demente. In: Del Ser, Peña J, Eds. Evaluación neuropsicológica y funcional de la demencia. Editorial Prous, 1994 Barcelona. 15 -Martín M, Salvadó I, Nadal S, Miji LC, Rico JM, Lanz P, Taussig MI. Adaptación para nuestro medio de la Escala de Sobrecarga del Cuidador (Caregiver Burden Interview) de Zarit. Rev Gerontol 1996; 6: 338-46.

16 -Beck AT, Steer RA, Brown GK. Manual for the Beck Depression Inventory-II. SanAntonio, TX: Psychological Corporation, 1996.

17 -Hälbig TD, Gruber D, Kopp UA, Schneider GH, Trottenberg T, Kupsch A. Pallidal stimulation in dystonia: effects on cognition, mood, and quality of life. J Neurol Neurosurg Psychiatry 2005;76:1713-6.

18 -Vidailhet M, Vercueil L, Houeto JL, Krystkowiak P, Lagrange C, Yelnik J, Bardinet E, et al. Bilateral, pallidal, deep-brain stimulation in primary generalised dystonia: a prospective 3 year follow-up study. Lancet Neurol 2007;6:223-9.

19 -Martínez-Martín P, Forjaz MJ, Frades-Payo B, Rusiñol AB, Fernández-García JM, BenitoLeón J, Arillo VC, Barberá MA, Sordo MP, Catalán MJ. Caregiver burden in Parkinson's disease. Mov Disord 2007;22:924-31. 
20 -Hälbig TD, Gruber D, Kopp UA, Schneider GH, Trottenberg T, Kupsch A. Pallidal stimulation in dystonia: effects on cognition, mood, and quality of life. J Neurol Neurosurg Psychiatry 2005;76:1713-6.

21 -Pillon B, Ardouin C, Dujardin K, Vittini P, Pelissolo A, Cottencin O, Vercueil L, et al. Preservation of cognitive function in dystonia treated by pallidal stimulation. Neurology 2006;66:1556-8.

22.-Blahak C, Wöhrle JC, Capelle HH, Bäzner H, Grips E, Weigel R, Kekelia K, Krauss JK.

Health-related quality of life in segmental dystonia is improved by bilateral pallidal stimulation. J Neurol 2008;255:178-82. 
Table 1. A: Open-label (A) and blind scores of the BFMDRS before and after surgery in each body segment (II) for $\mathrm{p}<0.05$ in comparison between baseline and one year follow-up; $(*)$ for $\mathrm{p}$ $<0.05$ in comparison between baseline and one year follow-up. Values are reported as means \pm SD. Values are reported as means $\pm \mathrm{SD}$.

A)

\begin{tabular}{|c|c|c|c|c|c|c|c|}
\hline & Baseline & Post-op & $\mathbf{p}$ & 6 Months & $\mathbf{p}$ & 12 Months & $\mathbf{p}$ \\
\hline \multicolumn{8}{|l|}{ Motor Score } \\
\hline Eyes & $0.29 \pm 0.71$ & $0.41 \pm 0.8$ & .317 & $0.39 \pm 0.9$ & .236 & $0.17 \pm 0.7$ & .236 \\
\hline Mouth & $1.86 \pm 2.92$ & $2.25 \pm 3.1$ & .705 & $0.84 \pm 1.5$ & .051 & $0.58 \pm 1.0$ & .054 \\
\hline Speech/swallowing & $4.54 \pm 5.14$ & $4.77 \pm 5.6$ & .763 & $3.10 \pm 3.1$ & .180 & $2.70 \pm 2.5$ & .285 \\
\hline Neck & $4.40 \pm 3.35$ & $4.25 \pm 3.3$ & .109 & $2.11 \pm 2.4$ & .008 & $2.00 \pm 2.0$ & .007 \\
\hline Right arm & $7.13 \pm 5.07$ & $6.83 \pm 4.9$ & .129 & $2.00 \pm 2.0$ & .001 & $1.82 \pm 2.2$ & .001 \\
\hline Left arm & $6.13 \pm 4.68$ & $5.72 \pm 4.2$ & .271 & $1.84 \pm 2.1$ & .001 & $1.88 \pm 1.8$ & .005 \\
\hline Trunk & $8.54 \pm 4.58$ & $7.33 \pm 3.9$ & .066 & $3.00 \pm 3.6$ & .001 & $3.05 \pm 3.3$ & .001 \\
\hline Right leg & $4.68 \pm 4.24$ & $5.50 \pm 3.8$ & .317 & $2.21 \pm 2.3$ & .005 & $2.64 \pm 2.9$ & .032 \\
\hline Left leg & $4.68 \pm 3.82$ & $4.94 \pm 2.9$ & .564 & $2.05 \pm 2.0$ & .002 & $2.17 \pm 2.2$ & .011 \\
\hline Total & $42.2 \pm 22$ & $42.02 \pm 21$ & .097 & $17.56 \pm 12$ & .001 & $17.05 \pm 12$ & .001 \\
\hline
\end{tabular}

\section{Disability score}

$\begin{array}{llllllll}\text { Speech } & 1.59 \pm 1.33 & 1.50 \pm 1.3 & .817 & 1.47 \pm 1 & .763 & 1.58 \pm 1 & .589 \\ \text { Writing } & 1.81 \pm 1.18 & 1.72 \pm 1 & .461 & 1.15 \pm 0.8 & .05 & 1.35 \pm 0.9 & .061 \\ \text { Eating } & 1.72 \pm 1.45 & 1.5 \pm 1.4 & .102 & 0.68 \pm 0.7 & .006 & 0.76 \pm 0.9 & .007 \\ \text { Swallowing } & 1 \pm 1.15 & 0.88 \pm 1 & .480 & 0.47 \pm 0.6 & .058 & 0.58 \pm 0.7 & .190 \\ \text { Hygiene } & 1.68 \pm 1.17 & 1.77 \pm 1 & .931 & 0.94 \pm 0.8 & .003 & 0.88 \pm 0.6 & .002\end{array}$




\begin{tabular}{llllllll} 
Dressing & $1.54 \pm 1.14$ & $1.5 \pm 0.9$ & .890 & $0.68 \pm 0.6$ & .002 & $0.58 \pm 0.6$ & .001 \\
Gait & $3.04 \pm 1.17$ & $2.83 \pm 0.9$ & .102 & $1.68 \pm 0.8$ & .001 & $1.88 \pm 0.9$ & .001 \\
Total & $\mathbf{1 2 . 4 0} \pm \mathbf{7 . 1 9}$ & $\mathbf{1 1 . 7 2} \pm \mathbf{6}$ & $\mathbf{. 3 3 0}$ & $\mathbf{6 . 6 3} \pm \mathbf{4 . 1}$ & $\mathbf{. 0 0 1}$ & $\mathbf{7 . 6 4} \pm \mathbf{3 . 9}$ & $\mathbf{. 0 0 1}$ \\
& & & & & & & \\
\hline
\end{tabular}

B)

\begin{tabular}{llll}
\hline & Baseline & $\mathbf{6}$ Months & $\mathbf{1 2}$ Months \\
& & & \\
& & & \\
Eyes & $0.33 \pm 0.2$ & $0.31 \pm 0.8$ & $0.23 \pm 0.7$ \\
Mouth & $1.87 \pm 2.54$ & $0.95 \pm 1.2$ & $0.76 \pm 0.6$ \\
Speech/ swallowing & $4.89 \pm 2.23$ & $4.15 \pm 2.9$ & $3.78 \pm 2.5$ \\
Neck & $5.13 \pm 2.45$ & $3.56 \pm 2.8(\mathbb{I I})$ & $2.9 \pm 2(*)$ \\
Right arm & $8.12 \pm 3.57$ & $6.98 \pm 1.9(\mathbb{I I})$ & $4.79 \pm 2.2(*)$ \\
Left arm & $7.45 \pm 3.38$ & $4.01 \pm 1.7(\mathbb{I I})$ & $3.8 \pm 1.8(*)$ \\
Trunk & $9.15 \pm 2.26$ & $3.89 \pm 2.8(\mathbb{I I})$ & $3.61 \pm 3.3(*)$ \\
Right leg & $4.72 \pm 2.67$ & $3.97 \pm 1.9$ & $2.97 \pm 2.9(*)$ \\
Left leg & $4.78 \pm 2.12$ & $3.18 \pm 1.5(\mathbb{I I})$ & $3.14 \pm 2.2(*)$ \\
Total & $\mathbf{4 6 . 4 \pm 2 1 . 4}$ & $\mathbf{3 1 . 0} \pm \mathbf{1 7 . 5}(\mathbb{\Phi})$ & $\mathbf{2 6 . 1} \pm \mathbf{1 6 . 3}(*)$ \\
& & & \\
\hline
\end{tabular}


Table 2. Effect size and magnitude of change observed for different measures.

$$
\text { Mean Magnitude of change Effect size* }
$$

\section{BFMDRS Motor score (blind)}

Baseline

6 Months

12 Months

BFMDRS Motor score (open)

Baseline

6 Months

12 Months

BFMDRS Disability score (open)

Baseline

6 Months

12 Months

SF-36

\section{Physical health summary}

Baseline

6 Months

12 Months

Mental health summary

Baseline

6 Months

12 Months

EQ-5D

\section{EQ-5D Index}

Baseline

6 Months

12 Months

VAS

Baseline

6 Months

12 Months
46.4

31.0

26.1

42.2

17.56

17.05

12.40

6.63

7.64

34.19

45.03

44.53

42.51

48.33

49.92
$-33.19 \%$

$-50.22 \%$

$-0.57$

$-0.86$

$-1.12$

$-1.14$

$-58.38 \%$

$-59.59 \%$

$-46.53 \%$

$-38.39 \%$

$-0.80$

$-0.66$
$31.70 \%$

$30.24 \%$

0.88

0.84

$13.70 \%$

$17.43 \%$

0.41

0.52

0.4103

0.6731

0.6315

$64.05 \%$

1.31

$53.91 \%$

1.10

40.45

69.12

$70.88 \%$

1.34

65.00

$60.70 \%$

1.14

For the effect size, values higher than $0.20,0.50$, and 0.80 represent small, moderate and great changes, respectively $(40,41)$. 


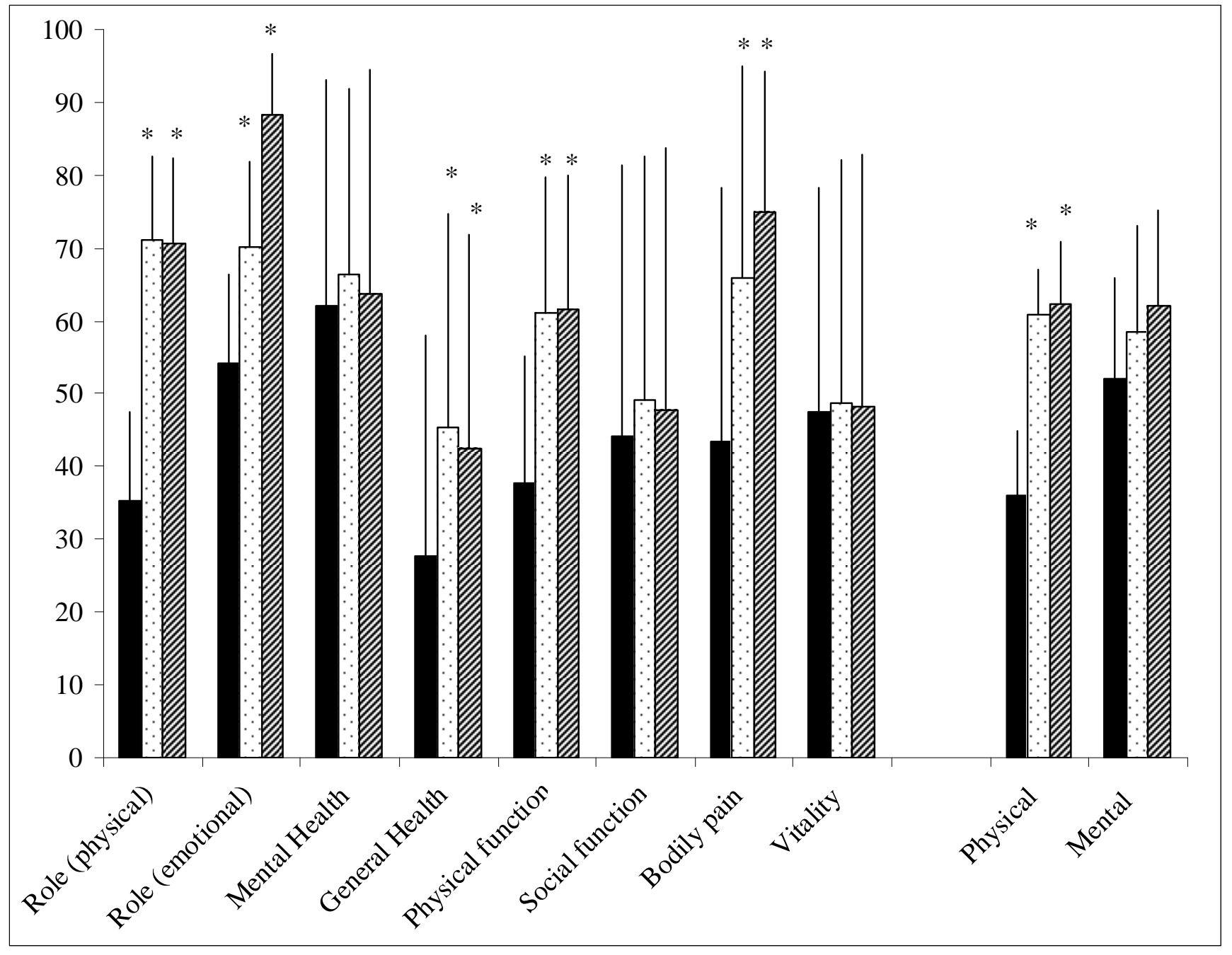

Figure 1. Mean SF-36 survey scores and standard deviations obtained preoperatively (black bars), at six months follow-up (dotted bars) and at 12 months follow-up (bars with lines). The dimension sub-scores for the eight categories are shown and the sums of the physical and mental dimensions are also represented. Scores are from 0 (worse) to 100 (best). Significant for $p<0.05$ is shown as *. 